Lexis Vol. XLIV (2) 2020: 445-482

\title{
El coa: glotopolítica y antropología criminal en Julio Vicuña Cifuentes (1910)*
}

\author{
Darío Rojas \\ Valentina Cáceres \\ Universidad de Chile
}

\section{RESUMEN}

En el presente trabajo analizamos la obra Coa: jerga de los delincuentes chilenos. Estudio y vocabulario (1910), de Julio Vicuña Cifuentes, desde un enfoque glotopolítico. Sostenemos que la representación ideológica del habla de los delincuentes chilenos (el coa), contenida en dicha obra, responde a un mecanismo de iconización, mediante el cual se legitima la política de disciplinamiento policial y carcelario del Estado chileno basándose en la comprobación científica de la supuesta condición degenerada del delincuente, reflejada en su lenguaje. Esta estrategia semiótica tiene como efecto glotopolítico último naturalizar la posición dominante de las élites socioeconómicas chilenas. Dicha representación responde al contexto chileno de comienzos del siglo XX, marcado por el surgimiento de la "cuestión social" y el positivismo ilustrado que marcó la institucionalización de los estudios antropológicos y lingüísticos en el Chile de ese periodo.

Palabras clave: ideología lingüística, historiografía lingüística, metalexicografía, argot, coa

\footnotetext{
El presente estudio se inscribe en los proyectos H850 "Filología, lingüística y archivo: aportes hacia una historia política de la lengua entre Europa y América Latina (mediados del siglo XIX-comienzos del siglo XX)” (U. Nacional de La Plata) y FFI2016-76874-P “Corpus diacrónico del español para el estudio de las actitudes lingüísticas en América y España (ss. XVIII y XIX)" (Ministerio de Economía y Competitividad, Gobierno de España).
}

https://doi.org/10.18800/lexis.202002.003 
Coa: Glottopolitics and Criminal Anthropology in Julio Vicuña Cifuentes (1910)

\begin{abstract}
In this paper we analyze the work Coa: jerga de los delincuentes chilenos. Estudio y vocabulario (1910) by Julio Vicuña Cifuentes, from a glottopolitical approach. We maintain that the ideological representation of the speech of Chilean criminals (coa) contained in said work responds to iconization, through which the criminal policy of the Chilean State is legitimized based on the scientific verification of the alleged degenerate condition of the criminals, reflected in their language. This semiotic strategy has the glottopolitical effect of naturalizing the dominant position of the Chilean socio-economic elites. This representation responds to the Chilean context of the early twentieth century, marked by the emergence of the "cuestion social" and illustrated positivism that marked the institutionalization of anthropological and linguistic studies in Chile during that period.

Keywords: language ideology, linguistic historiography, metalexicography, argot, coa
\end{abstract}




\section{Introducción}

En el presente artículo nos proponemos analizar la obra Coa: jerga de los delincuentes chilenos. Estudio y vocabulario, publicada en 1910 en Santiago por el abogado, escritor y folklorista Julio Vicuña Cifuentes, desde el enfoque teórico-metodológico de la glotopolítica. Este enfoque (Arnoux 2000) representa un esfuerzo por articular una teoría sociopolítica sobre el lenguaje y las lenguas, distanciada críticamente de los enfoques formalistas (generativismo, estructuralismo, etc.) desde un punto de vista interdisciplinario, sobre todo dialogando con la teoría crítica de inspiración marxista y postestructuralista (Felluga 2015). Entre las premisas fundamentales del enfoque glotopolítico, que cuenta con una abundante bibliografía descriptiva en el ámbito latinoamericano (Arnoux, Del Valle y Duchêne 2019), se encuentran las siguientes:

1) El lenguaje es esencialmente una práctica social dinámica, emergente y situada en contexto (Harris y Wolf 1998), y, por tanto, constitutiva de las identidades sociales de los hablantes; es decir, el lenguaje es un fenómeno de naturaleza radicalmente política, inseparable de la constitución de relaciones asimétricas de poder (Joseph 2017).

2) Lo único real es el uso lingüístico, la comunicación; en cambio, las lenguas (dialectos, sociolectos, o cualquier término con que se quiera apuntar a la langue saussureana), más que realidades objetivas comprobables empíricamente, son construcciones sociales, representaciones constitutivas de los imaginarios sociales (Makoni y Pennycook 2007, Taylor 1997). Aceptada su naturaleza imaginada, estas representaciones, constituidas por creencias, actitudes, etc., acerca de los hablantes y sus formas de hablar, no son "objetivas", sino que están influidas por los posicionamientos políticos de quienes las enuncian (Joseph 2017: 282-283); en otras palabras, tienen naturaleza ideológica, por lo cual puede entendérselas como ideologías lingüisticas: "sistemas de ideas que articulan nociones del 
lenguaje, las lenguas, el habla y/o la comunicación con formaciones culturales, políticas y/o sociales específicas” (Del Valle y Meirinho-Guede 2016: 629).

3) Aceptado lo anterior, toda representación sobre el lenguaje es ideología lingüística, tanto aquella sostenida por los hablantes legos como aquella sostenida por los especialistas. Esto quiere decir que la "ciencia del lenguaje" no es ideológicamente neutra (Joseph y Taylor 1990, Swiggers 2018), pues "language and the institutions around it are always embedded in history. Disciplines, co-constitutive with such objects, emerge and develop in tandem with struggles over specific social needs and demands" (Del Valle 2019). Esto quiere decir que, igual como los conocimientos científicos "no están apartad[o]s de la historia (de la lucha de clases): constituyen 'desprendimientos' especializados de las ideologías prácticas en el terreno de la producción de conocimientos" (Pecheux [1975] 2017: 164), las teorías lingüísticas y discursos metalingüísticos especializados son emergencias surgidas de la historia, esto es, de las condiciones específicas de la praxis de una sociedad dada (Laurendeau 1990: 212).

4) Finalmente, adoptar el enfoque glotopolítico implica el análisis crítico de los discursos en que se manifiestan las prácticas lingüísticas o las representaciones ideológicas sobre ellas, entiendiendo por discurso la "articulación de un texto y un lugar social” (citado en Arnoux 2006: 15). Es decir, se adopta una perspectiva metodológica empírica que conlleva un trabajo de indagación en el archivo histórico, y que al mismo tiempo supone la constante consideración de las condiciones materiales de producción de estos textos.

En su parte principal, la obra que analizamos adopta las convenciones del género lexicográfico, de modo que puede considerársela en la práctica como un diccionario. Siguiendo el enfoque glotopolítico y sus aplicaciones metalexicográficas, que ya cuenta con una importante tradición en el ámbito hispanoparlante (Huisa 
2013, Lauria 2011, Rodríguez Barcia 2016), entendemos el diccionario como discurso, es decir, como práctica social en contexto. En este sentido, adoptamos los principios fundamentales de los estudios críticos del discurso lexicográfico (Chen 2019), entre los que es necesario considerar, primero, que "lexicography and its products, dictionaries, are never value-free, apolitical or asocial. Instead, they are subject to ideology, power, and politics" (Chen 2019: 362); segundo, que "any lexicographical text (the dictionary proper) is a social act, a product of the socio-political and historical context in which it exists" (Chen 2019: 373); y, tercero, que "objectivity and authority of the dictionary is a discursive construct" (Chen 2019: 373).

La consideración de las representaciones metalingüísticas ( $\mathrm{y}$ los discursos que las vehiculan) en el marco de la constitución de relaciones desiguales de poder es importante para comprender adecuadamente la obra de Vicuña debido a la naturaleza del objeto lingüístico de la que esta trata: el coa, nombre que recibe el antilenguaje (Halliday 2001) usado por los delincuentes chilenos. Sus hablantes pertenecen a un sector muy específico de los grupos subalternos $^{1}$, que en Chile históricamente han sido objeto de representaciones negativas, de exclusión política y de marginación económica (Pinto 2008a, 2008b). En consecuencia, proponemos entender los discursos sobre el coa como discursos sobre el lugar de sus hablantes (y de los sectores subalternos de los que forman parte) en la nación chilena de comienzos del siglo XX, problema suscitado por el surgimiento de la "cuestión social” a fines del siglo XIX. Por el lugar institucional en que se inserta la obra (el programa de investigación de la Sociedad de Folklore Chileno, asociado fundamentalmente al Instituto Pedagógico de la U. de Chile), se puede sostener además que esta obra forma parte del dispositivo de reconocimiento y control estatal articulado desde el campo científico,

\footnotetext{
En general, el uso gramsciano de este término, ampliamente usado hoy en la teoría crítica (especialmente en los llamados estudios subalternos), refiere a "any group that is excluded from the dominant hegemony of a society and is thus denied the same benefits of the dominant class" (Felluga 2015: 295).
} 
con el que se pretendía conseguir un cartografiado completo de la población y el territorio de la nación.

Tanto la historiografía de la lexicografía chilena (Matus 1994, Rojas 2010, entre otros) como la historiografía de las ideologías lingüísticas en Chile (Rojas 2015, 2017, entre otros) han desatendido por completo la tradición específica de los diccionarios de coa, a la que da inicio la obra de Vicuña. La historiografía de la lexicografía del coa chileno, en suma, está por hacerse, y nuestro estudio puede considerarse una contribución inicial al remedio de esta laguna, que contrasta con la existencia de importantes estudios de alcance general sobre la lexicografía del caló español (Buzek 2011) o sobre los diccionarios de cant del ámbito angloparlante (Coleman 20042010, Sorensen 2017).

Antes de pasar al análisis de la obra de Vicuña, y para preparar el terreno para una interpretación glotopolítica de la misma, la situaremos en el contexto del auge del positivismo ilustrado en el Chile de comienzos del siglo XX, a fin de poner especial énfasis en los elementos contextuales clave para comprender su sentido glotopolítico: su inscripción en el proyecto investigativo de la Sociedad de Folklore Chileno y su vinculación con la formación de un aparato carcelario en Chile.

2. Positivismo ilustrado y domesticación del subalterno en el Chile de comienzos del siglo XX: la Sociedad de Folklore Chileno y la criminología positivista

Las últimas décadas del siglo XIX atestiguaron a lo largo de toda Latinoamérica tendencias a la modernización, entendida esta como un proyecto político abarcador de distintas dimensiones (económica, cultural, social, etc.) pero que en lo fundamental pretendía insertar a las naciones americanas en el mundo percibido como moderno (Europa y Estados Unidos). Este proyecto consideró las dimensiones de la economía (integración al mercado capitalista mundial e industrialización), lo social (inmigración masiva y aparición/emergencia de nuevos actores sociales) y lo político (regí- 
menes liberales pero fuertemente restrictivos y excluyentes), junto con el sustrato ideológico clave del positivismo ilustrado. Uno de los supuestos básicos de este proyecto modernizador es el supuesto de la racionalidad-técnico científica ["la convicción de que la ciencia y la técnica son las vías fundamentales para lograr la plenitud del hombre y la sociedad" (Subercaseaux 2011: 362)], que permite entender la relevancia que cobra la ciencia como epistemología y como método para la organización del Estado en esta época.

Si en las primeras décadas de independencia de las repúblicas hispanoamericanas, predominó un interés naturalista por la geografía y los recursos naturales, con el avance del siglo el interés también "se extendió a otros campos del saber como la Historia o la Filología y, ya hacia finales del siglo, la Antropología” (Carreras y Carrillo Zeiter 2014: 13). Por otra parte, en el entresiglo (XIX-XX), se vivió un crecimiento pronunciado de la institucionalización de la ciencia en el marco de universidades, revistas y sociedades. En todo este periodo, además de una utilidad práctica, la ciencia tiene una razón de ser ideológica, pues la definición de cuáles intereses u objetos de estudio eran prioritarios dependió de los intereses de los Estados, y de la manera en que estos querían representar (para naturalizar) la posición de los distintos grupos culturales en la nación (Mora 2018: 133-134).

En Chile, los patrones generales del ámbito latinoamericano, que acabamos de caracterizar, se cumplen de forma bastante regular. A fines del siglo XIX, buena parte de los intelectuales más importantes del fin de siglo chileno adscribieron a la actitud cientificista de corte ilustrado y positivista (Subercaseaux 2011:398). Entre los proyectos en que se materializó el empuje de esta corriente, se encuentran "la institucionalización, expansión y modernización de la educación laica" y "la constitución de diversas disciplinas en el ámbito de las ciencias sociales y humanas" (Subercaseaux 2011: 399). Un ejemplo de la indisociabilidad de política científica y política educativa en este periodo es la creación del Instituto Pedagógico de la Universidad de Chile en 1889 y la institucionalización de las ciencias del lenguaje bajo su alero. El Instituto Pedagógico fue fundado por 
iniciativa estatal gracias a las gestiones de Valentín Letelier, quien recomendó seguir el modelo pedagógico alemán y contratar especialistas científicos de esa nacionalidad con el fin de modernizar y secularizar la formación disciplinar de los profesores de escuela en Chile (Sanhueza 2013).

En el contingente de científicos alemanes venían Federico Hanssen, filólogo que se dedicaría a la gramática histórica castellana, y Rodolfo Lenz, lingüista encargado de la enseñanza de lenguas modernas. Ambos se habían formado en la escuela hegemónica en las ciencias del lenguaje de ese entonces: la de los neogramáticos de Leipzig. Como para casi toda la lingüística científica del siglo XIX, su interés principal era el cambio lingüístico, pero los neogramáticos, sobre bases positivistas, introdujeron la novedad de considerar como objeto de estudio primario el cambio tal como se estaba desarrollando en boca del pueblo, en lugar de observarlo en testimonios literarios de la antigüedad. A partir de estas coordenadas, Lenz, en particular, articuló un programa de investigación centrado en el castellano vulgar chileno y el mapuzugun y en sus interinfluencias (Ennis 2016, Pavez 2015). Con ello, introdujo una fractura importante en la tradición de estudios del lenguaje en Chile, que durante todo el siglo XIX fue normativista y puso énfasis en la erradicación de los “vicios” del castellano vulgar chileno, entre los cuales se incluía precisamente el indigenismo léxico (Rojas 2017).

Además de interesarse por el lenguaje del pueblo chileno y de los mapuche, Lenz mostró desde temprano un marcado interés por el folklore, lo que lo llevó a fundar en 1909 la Sociedad de Folklore Chileno (en adelante, SFCh), en cuyo marco Julio Vicuña publica su obra sobre el coa. El Programa de la SFCh (Lenz 1909) revela que la institución, organizada en torno a un número pequeño de figuras centrales —Rodolfo Lenz, Ramón Laval y Julio Vicuña, entre otros (Dannemann 2010)_, se constituyó como una entidad que, con apoyo del Estado (representado básicamente por el Instituto Pedagógico) y al mismo tiempo al servicio de este, se propuso principalmente promover y facilitar los estudios sobre el folklore en Chile, más que ejecutar investigaciones por sí misma. Estos estu- 
dios se entendían como de naturaleza científica de acuerdo con un enfoque positivista, es decir, basándose en el estudio de material empírico y la clasificación y análisis sistemático de los materiales.

Siguiendo los dictados de la ciencia antropológica de la época (la etnología), la SFCh se proponía contribuir a conocer la "vida síquica" o mentalidad del pueblo chileno desde una matriz evolucionista que implicaba que el conocimiento de los sectores más "atrasados" (como los sectores populares o los pueblos indígenas) permitiría arrojar luz sobre etapas pasadas de la humanidad, así como facilitar el avance de la civilización y el progreso. El folklore sería una de las manifestaciones materiales (por tanto, observables empíricamente) de esa mentalidad (no observable directamente), y además una manifestación que corría riesgo de desaparecer bajo el avance arrollador del progreso moderno, de modo que la ciencia del folklore era una actividad de rescate de ese patrimonio.

En el delineamiento que ofrece Lenz en el programa, la lingüística descriptiva ocupa un rol fundamental en el levantamiento de materiales empíricos, no solo por manifestarse el folklore a través del lenguaje (como discursos: relatos, adivinanzas, poesía popular, etc.), sino porque el "lenguaje vulgar" (el de los grupos subalternos) reviste un interés inmanente al ser reflejo fiel del pensamiento popular. Este estudio del lenguaje subalterno supone una perspectiva diferencial (Zimmermann 2018) que implica a su vez una visión jerarquizante donde dicho lenguaje se define negativamente en su relación de diferencia (conceptualizada como déficit) respecto del lenguaje "normal" (el de las clases dominantes).

La centralidad del estudio del castellano "vulgar" chileno en el conocimiento de la sicología de los sectores subalternos motiva que una parte importante de la producción bibliográfica asociada a la SFCh tenga por foco distintos aspectos de las formas de hablar de dichos sectores. Así se puede ver en el interés por el elemento indígena del léxico popular (el Diccionario etimológico de Lenz, publicado entre 1905 y 1910), el coa o lenguaje de los delincuentes chilenos (Coa de Julio Vicuña, publicado en 1910) y el habla de Chiloé (Chiloé y los chilotes, de 1914, y el Diccionario manual 
isleño, de 1921, ambos de Francisco Cavada). Ellas apuntan a distintas características articuladoras de la condición subalterna de sus hablantes, y relevantes sociopolíticamente en el contexto de las primeras décadas del siglo XX: en Lenz, el mestizaje y lo mapuche, relevante sobremanera en el contexto post Ocupación de la Araucanía por parte del Estado chileno; en Vicuña, la delincuencia, asociada tendenciosamente a los sectores populares urbanos, saliente en el marco de la organización de un dispositivo estatal de control del crimen y de construcción de un “sujeto criminal” (León 2015a); y en Cavada, la provincialidad fronteriza, relevante en el marco de recientes expansiones territoriales del Estado chileno, y aun más atingente en el caso de Chiloé por su todavía entonces inacabada chilenización y su fama de zona singular en diversos aspectos.

En estos discursos, se despliega un proceso de construcción de una otredad lingüística que es, al mismo tiempo, una puesta en perspectiva de la diferencia lingüística de los sujetos subalternos respecto de la lengua de Estado, de acuerdo con la cual esa diferencia se termina viendo como una deficiencia. La implicancia política de dicha representación metalingüística es que contribuye a naturalizar una imagen de inferioridad (intelectual, moral, etc.) de los subalternos, que termina justificando su posición subyugada en la estructura económica del Chile de esa época, y que, por otro lado, a la vez naturaliza la posición dominante de las élites. Dicho de una forma gráfica, se trata de la domesticación de los grupos subalternos. Decir que se trata de domesticación implica, por un lado, activar el sentido de doméstico como 'de la casa, del hogar, o relacionados con ellos' (CLAVE, s.v. doméstico), entendiendo al Estado-nación como esa casa/hogar. En este marco, la domesticación conlleva pensar en la asimilación, en el hacer pertenecer al lugar donde uno habita, pero sin poder soslayar que, al mismo tiempo, ese hacer pertenecer incluye la otorgación de un lugar subordinado. Por otro lado, usar este término permite destacar el sentido de domesticar como 'referido a una persona, hacer que sea más agradable y de carácter menos áspero' (CLAVE, s.v. domesticar), definición que no podemos dejar de vincular con la frase del Diccionario etimológico de Lenz sobre 
"hacer simpática la figura del indio" (Lenz [1905-1910] 1979: 41) a ojos del Estado para propiciar su civilización y asimilación a la nación chilena.

En este sentido, cabe hacer hincapié en que el interés del aparato estatal de producción de conocimientos por levantar información acerca de los sujetos subalternos, en particular para el caso que nos ocupa en este trabajo, guarda directa relación con el surgimiento de la llamada cuestión social entre 1880 y 1920 (Grez 1995). Si en la época colonial la población indígena y los mestizos fueron explotados brutalmente como fuerza de trabajo agrícola por la clase dominante (compuesta por españoles y criollos), la llegada de la Independencia no cambió sustancialmente su situación, pues esta fue obra principalmente de la élite criolla, que se aseguró de mantener su posición de privilegio (Collier y Sater 1998: 35-38). En el proyecto de Estado-nación impulsado por esta élite, desde muy temprano se puede ver una imagen negativa de la otredad subalterna (Pinto 2008a, 2008b). En la segunda mitad del siglo, la consolidación de la hegemonía conservadora instalada en la primera mitad del periodo y la expansión de la economía basada en un modelo exportador no significaron un mejoramiento de la situación de estos grupos. Por el contrario, mientras la clase alta se había enriquecido hasta niveles ostentosos, los grupos subalternos habían empeorado su situación material y espiritual. En el campo, los llamados gañanes, en su búsqueda de simple sobrevivencia migraron en masa hacia las ciudades y hacia las salitreras del norte para encontrar medios de subsistir. En las ciudades, sin embargo, las condiciones no eran las mejores: $\tan$ solo al alborear el siglo XX se instalaron los primeros rudimentos de redes de alcantarillado, y "todavía en 1920 Santiago no contaba con un suministro de agua potable adecuado" (Collier y Sater 1998: 161), de tal manera que las enfermedades contagiosas asolaban a buena parte de la población. A la pobreza generalizada se asociaba una preocupante tasa de criminalidad.

Estos problemas no fueron privativos del periodo en cuestión; se trata más bien de que en estos años el problema se agravó a tal punto que se hizo ineludible para las élites, de manera que empiezan 
a surgir debates en la esfera pública y luego intervenciones del Estado para intentar hacerse cargo de los problemas causados por la extrema desigualdad económica asociada a la acumulación capitalista que encuentra su etapa culminante en la época de la explotación del salitre, iniciada tras la Guerra del Pacífico (1879-1884).

Una de las reacciones fue la implantación de mecanismos de control de los sujetos subalternos, "políticas moralizadoras que apuntaban a integrarlos a la sociedad”, “aquietarlos y sujetarlos al hogar y a la patria” (Pinto 2008b: 132). En lo que atañe específicamente a la criminalidad, no puede soslayarse que, a pesar de las buenas intenciones, la cientifización del disciplinamiento carcelario en Chile (estudiada en profundidad por León 2015a) se inscribe en una estrategia de legitimación del orden hegemónico. La política estatal en lo relativo a la delincuencia, desde el auge del positivismo, "logró un respaldo más digno y respetable ante la colectividad" y al mismo tiempo se benefició de la naturalización de las “aprehensiones que tanto las autoridades políticas-gubernativas como las élites urbanas tenían respecto de los sectores populares" (León 2015b: 54). Por ello, en Chile, como en otras partes, la cuestión social habitualmente se vinculó a una "cuestión criminal”, pues, en la percepción de las élites gobernantes, el sujeto popular y el sujeto criminal se solapaban de forma importante, de modo que la antropología criminal terminó "reafirmando bajo criterios 'científicos' antiguos prejuicios de corte racista y clasista” (León 2015b: 67). Así, la criminología positivista condujo a "concluir que las conductas delictivas eran una característica inherente a ellas [las clases subalternas]” (León 2015b: 65).

\section{Estructura general y origen de la obra}

Dentro de las obras publicadas por los miembros de la SFCh, la obra de Vicuña (en adelante, Coa) es la única que aborda una variedad determinada en términos puramente sociolectales, y su interés para la disciplina quedaba establecido en el Programa de la SFCh, en el marco de los "vocabularios especiales para cada oficio", entre 
los cuales "tambien conviene estudiar aparte [...] el lenguaje de los pillos (la coa)" (Lenz 1909: 17).

Esta obra, según reza la portada, sería "presentada impresa por su autor al Congreso Científico Internacional Americano que se reunirá en Buenos Aires, en Julio de 1910" (1909); con lo cual de inmediato se intenta dejar en claro al lector su naturaleza de estudio científico. Consta de 144 páginas, de las cuales 50, aproximadamente, corresponden a una "Introducción" y otros elementos paratextuales (bibliografía, tabla de abreviaturas, entre otros). La "Introducción", junto con discutir con base en bibliografía especializada el concepto de coa y de jerga, presenta una caracterización y ejemplificación de los principales procedimientos de lexicogenesia que particularizan al coa; este sería el "estudio" anunciado en el título. El resto del texto corresponde al "vocabulario" del título, es decir, la nomenclatura o lemario, que consta de aproximadamente 750 entradas lexicográficas, compuestas cada una de un lema, una marca gramatical, una definición, un ejemplo (opcional), un paréntesis etimológico (opcional) e indicaciones de la restricción geográfica de uso de la palabra.

De acuerdo con una breve nota preliminar titulada "Dos palabras", Vicuña compuso lo fundamental de su texto en 1903, de modo que puede suponerse que esto explica que haya sido una de las obras más tempranamente publicadas, de las asociadas a la SFCh. Según relata el autor en ese mismo texto, para su elaboración contó con el apoyo de funcionarios del Ministerio de Justicia, el subsecretario Enrique Matta Vial y el estadístico Francisco de Béze, quienes le facilitaron acceso a directores y alcaides "de la mayor parte de los establecimientos penales de la República” (Vicuña 1910: 43-44); de ahí la posibilidad de poner marcas geográficas en las entradas y cumplir así con el desideratum implicado en el Programa de la $\mathrm{SFCh}$ respecto de conocer las variedades regionales del lenguaje popular chileno.

Vicuña envió a sus facilitadores un "interrogatorio", que debemos entender como la aplicación de una encuesta por correspondencia a aquellos observadores privilegiados del lenguaje de los delincuentes. A partir de esta base, depuró el material “ayudán- 
dose con nuevas y más directas investigaciones” (1910: 44), aunque lamentablemente no indica si es que "más directas" significa que se entrevistó con reos. Sin embargo, la "Bibliografía” (1910: 44-48) lista al menos dos fuentes secundarias: sendas ediciones de El guardián de policía del comisario Guillermo Ávila Money, publicadas en 1902 (con un anexo de 194 voces) y 1908 (128 voces). Igualmente, registra una fuente primaria: "La poesía de los delincuentes, pequeña colección de versos recogidos en las cárceles y presidios. M S. de propiedad del autor" (1910: 46).

Este último dato es interesante porque permite apreciar que la indagación de Vicuña acerca del mundo delictual también transitó por el derrotero de las indagaciones folklórico-literarias (el punto I.A, "Poesía”, del Programa), tal como hizo en las principales de sus obras eruditas publicadas (Romances populares y vulgares recogidos de la tradición oral chilena, 1912, y Mitos y supersticiones recogidos de la tradición oral chilena, 1915; y sus estudios sobre métrica castellana publicados en el Boletín de la Academia Chilena en 1918). De hecho, considerando además que Vicuña se destacó principalmente como poeta y conocedor de la literatura grecolatina, española y renacentista (Silva Castro 1944), podría pensarse que su interés por el coa como problema lingüístico fue secundario respecto de su interés por las manifestaciones literarias de la cultura carcelaria, de lo cual también da cuenta la impresión de desinterés por su propia obra lingüística que se puede entrever en su declaración de que "si el tema interesa y otros lo tratan, á ellos corresponderá la tarea de corregir y ampliar este ensayo, en el cual, probablemente, no tendré yo oportunidad de volver á ocuparme" (Vicuña 1910: 44).

4. Influencias: Salillas y la antropología (lingüística) criminal Buena parte de la "Introducción" de la obra está dedicada a la definición y caracterización de la variedad lingüística estudiada por Vicuña. Para ello, toma como referentes las indagaciones de otros autores que se habían ocupado antes que él del problema, listados oportunamente en la "Bibliografía”. Entre ellos sobresale el crimi- 
nólogo español Rafael Salillas (1854-1923), principal representante del positivismo científico aplicado a la criminología en el mundo castellanohablante de fines del siglo XIX, lo cual precisamente explica su rol de referente para Vicuña. Baste apuntar que el chileno califica al español de "autor del mejor estudio publicado hasta ahora sobre las jergas españolas” (Vicuña 1910: 11). El chileno incluye en su bibliografía dos obras de este autor: El delincuente español: el lenguaje. Estudio filológico, psicológico y sociológico, con dos vocabularios jergales, de 1896; y la segunda parte de esta: El delincuente español: Hampa. Antropología picaresca, de 1898, de las cuales la primera sirve de modelo directo para la propia obra del chileno.

A fines del siglo XIX, la antropología criminal gozaba de un gran empuje en Europa, a partir de los escritos del italiano Cesare Lombroso (1835-1909), también ampliamente citado por Vicuña. La antropología criminal se asoció fuertemente al movimiento de reforma penitenciaria, constituyendo una aplicación de los principios del positivismo a unas de las cuestiones sociales más candentes en la época: la delincuencia. Se constituyeron en esta época aproximaciones científicas al estudio de los criminales, a partir de bases evolucionistas (que llevarán a hablar de los delincuentes como "degenerados" y portadores de "atavismo") y con un afán de clasificar (con fines predictivos) a los delincuentes tanto a partir de bases fisiológicas (indicios morfológicos de criminalidad) como síquicas, respaldada en estudios "experimentales". Salillas se erige como principal representante de la antropología criminal positivista en España y como contribución específica desarrolla una "teoría nutritiva de la delincuencia” (Calera 1986: 92), que en síntesis postula que "el delincuente es una consecuencia de la falta de alimento del individuo durante su etapa de desarrollo, que provoca un estado de degeneración orgánica que es el responsable de la morfología y del comportamiento delincuente" (Calera 1986: 93). Por otra parte, el correlato síquico de los efectos fisiológicos de la malnutrición correspondería a "una actividad mental que supone aptitudes para adquirir pero no para producir por lo que su actividad ha de basarse en recursos parasitarios" (Fernández 1976: 208). 
La obra de 1896 ya mencionada es en la que expone sus ideas acerca del papel que el estudio del lenguaje desempeña en el conocimiento científico de la criminalidad. Salillas, partiendo de la idea de que el lenguaje es fundamentalmente un mecanismo para exteriorizar ideas, afirma que "entre la sociedad [criminal] y su lenguaje existe una relación de intimidad caracterizada por peculiaridades sociológicas, psicológicas y filológicas” (1896: 11). En consecuencia, para conocer mejor a la sociedad criminal hay que estudiar su "lenguaje bastardo" (1896: 9), la jerga, pues habría una relación isomórfica entre patrones síquicos (vinculados a factores del medio y fisiológicos) y patrones lingüísticos. La principal función de la jerga, en este marco, sería el "disimulo por representaciones, o sea, la permutación de imágenes, consecuencia de la versión particular que el delincuente tiene de las cosas” (Fernández 1976: 172).

Otro punto importante del pensamiento lingüístico de Salillas es que no considera que la jerga sea "anómala” respecto del lenguaje "normal” en cuanto a cuestiones de estructura gramatical o fonética: "Sus formas filológicas se encentran en la lengua originaria" (Fernández 1976: 173). En este sentido, se aplica a la jerga la idea de Salillas de que la criminalidad tiene una condición parasitaria, en el sentido que explicamos más arriba. Sin embargo, al mismo tiempo "sus formas representativas obedecen a un modo de vivir y también a un modo de sentir determinantes" (Fernández 1976: 173). Con lo de "formas" o "modos representativos" se refiere a cuestiones léxico-semánticas: la calificación por atributos, la simplicidad de las representaciones y la exageración de las representaciones, todo lo cual podría explicarse por un primitivismo mental, pero, sobre todo, respondería “a las peculiares condiciones de vida, siempre sobresaltada, del delincuente” (Fernández 1976: 174). Si las formas del lenguaje jergal lo unen con el lenguaje "normal”, "la diferencia esencial entre el lenguaje de la sociedad normal y el lenguaje de la germanía, radica en la distinta índole representativa” (Fernández 1976: 176).

Las ideas antes explicadas, propias de la antropología criminal positivista europea de fines del siglo XIX en general y de la versión 
española de esta desarrollada por Salillas en particular, son las que sirven de sustento para la aproximación de Vicuña al concepto de coa.

\section{Representación ideológica del coa en Vicuña}

En primer lugar, la idea de que las jergas delictuales no son más que extensiones "parasitarias" de la lengua común y que se distancian de la misma fundamentalmente por los modos de representación particulares de la siquis criminal, está presente claramente en el párrafo que abre la introducción de Coa:

Las jergas no son propiamente idiomas, ni aun dialectos: son apenas extensiones de la lengua común, en que, como dice Lombroso, "mientras las asonancias generales y el tipo gramatical y sintáctico se conservan ilesos, está mudado completamente el léxico". Luego veremos que estos cambios se refieren más á alteraciones en la significación usual de las palabras, que á la formación e introducción de nuevos vocablos (Vicuña 1910: 3).

Nótese que la negación de su condición de "idioma" o "dialecto" conlleva una jerarquización según la cual las jergas serían variedades de alguna manera inferiores a los idiomas o dialectos.

A pesar de que las jergas son representadas por Vicuña como variedades lingüísticas bastante recurrentes y comunes, destaca a la vez que la jerga de los delincuentes reviste un interés especial, pues, por "servir de instrumento á conspiraciones tenebrosas contra la sociedad, despierta un interés que ninguna de sus afines osará nunca disputarle" (1910: 5). Cabe preguntarse: ¿interés de quién? Su condición de instrumento del delito sugiere que la respuesta es el de los administradores de la justicia. Vicuña parece entender con claridad que, más allá del fin "puramente científico" que se le pueda atribuir en el marco del Programa de la SFCh, el estudio del coa forma parte del estudio de la criminalidad desde los aparatos del Estado con el fin de controlar a parte de la población. Se trata, entonces, de un conocimiento aplicado y de un conocimiento al servicio de la política. Recuérdese que el propio Vicuña relata cómo su investigación fue no solo permitida, sino que facilitada por la cooperación 
de agentes del aparato policial, y que entre sus bases fundamentales de información estaban los textos del comisario Ávila Money, que eran básicamente manuales de procedimiento para los gendarmes y policías. Para Vicuña, tal instrumentalización política del estudio lingüístico del coa es posible porque "la jerga constituye la documentación sicológica y sociológica más preciosa para el estudio del hombre criminal" (1910: 17-18). Al ser el estudio del coa el estudio de la mente y la sociabilidad criminal, y no cualquiera, sino el de la "documentación más preciosa”, puede convertirse en un insumo valiosísimo para diseñar políticas de control y prevención de la criminalidad en el contexto chileno.

Las primeras páginas de la "Introducción” están dedicadas a discutir las teorías de varios autores (Lombroso, Salillas, Dellepiane, Quirós y Llanas Aguilaniedo, Larchey, Niceforo y Sighele, entre otros) acerca del origen de las jergas, poniendo especial énfasis en el disimulo u ocultamiento como factor explicativo. Vicuña en esta sección deja ver la visión positivista de que la condición ("moral e intelectual”) de sus autores encauza las características de la jerga, a la manera de una "ley biológica á la cual pueden momentáneamente substraerse, pero de la que no les es dado independizarse" (1910: 12). En consecuencia, aunque el disimulo pueda ser factor general de formación de las jergas, si sus hablantes son criminales, estas se verán imbuidas del "espíritu” propio de los criminales, "que cuando se evapora del fondo del organismo pervertido para tomar forma en la jerga, tiene sus cristalizaciones propias” (1910: 13).

Hechas estas aclaraciones previas, Vicuña llega a ofrecer una definición de la jerga delictual: "Es el lenguaje acomodado á su vida y entendimiento, que usan los delincuentes habituales y asociados en su lucha con el medio" (1910: 14). El coa sería la versión específica de los delincuentes chilenos, que en lo relativo a su "formación y desarrollo en nada difiere de sus congéneres de los demás países” (1910: 19), pero que, "por tratarse de un pueblo joven aislado en el extremo de un continente” (1910:19) carece de ciertos elementos tradicionales y extranjerismos (por ejemplo, "personificaciones de carácter mitológico, histórico o literario”; 1910: 29) comunes 
en las jergas de "países de larga historia y de fronteras próximas y pobladas” (1910: 20), y, además, contiene “modificaciones de carácter étnico, que vienen a constituir el rasgo propio, la sola originalidad de esta clase de producciones" (1910: 20). Globalmente, sin embargo, Vicuña enfatiza que las jergas de distintos países tienen mucho de común en cuanto al "procedimiento filológico, que corresponde exactamente a la uniformidad de tendencias de sus autores" (1910: 20); es decir, un delincuente es un “degenerado" en cualquier parte, y por eso todas las jergas son en lo fundamental parecidas en sus mecanismos léxico-semánticos que revelan una mentalidad similar.

La exposición detallada de estos esquemas, junto con responder al requisito positivista de exposición meticulosa de afán clasificatorio, permite a Vicuña poner de relieve la base común de las jergas que se manifiesta en el coa. A continuación, reproducimos la lista jerárquica de esquemas que Vicuña pone en las páginas 20-21, y añadimos entre corchetes algunos ejemplos del coa ofrecidos más adelante por el propio autor:

1. Alteraciones fonéticas:

a) Inversiones. [jermu < mujer; tapla < plata]

b) Eliminaciones. [lolo $<$ pololo 'robo pequeño'; chale $<$ chaleco]

c) Adiciones. [huaracaquear < buaraquear; monronrero < monrero]

d) Substituciones. [chute $<$ futre; milico $<$ militar]

e) Fusiones. [carecallo < cara de caballo 'desvergonzado']

2. Formas de representación sensible:

a) Onomatopeyas. [nafo 'pañuelo de bolsillo']

b) Automatismos. [tete 'vergonzoso']

c) Paronomasias. [Arturo $<$ ar tiro $<$ al tiro]

d) Seudo etimologías. [Filomena 'cuchillo']

3. Formas de representación sugestiva:

a) Metáforas. [pala 'cuchara'; paloma 'camisa'] 
b) Metonimias. [lámina 'azote']

c) Sinécdoques

d) Antonomasias. [Don Pancho 'barra de hierro para forzar cerraduras']

e) Antífrasis. [mudo 'ganso']

f) Ironías. [amigo 'alcaide de la cárcel'; ángel 'secretario del juez']

g) Eufemismos. [trabajo 'robo'; deber 'coito']

4. Calificaciones adjetivas por atributos. [agrio 'lima'; vidriosos 'ojos']

5. Personificaciones. [Don José Cumplido 'pene’]

6. Arcaísmos. [calamorro 'candado']

7. Neologismos. [“son bastante numerosos y se señalan por sí mismos"; 30]

8. Extranjerismos. [rin 'anillo'; manyar 'comer']

9. Formas de origen desconocido. ["no las precisaremos aquí, porque no estamos ciertos de poder distinguirlas exactamente"; Vicuña 1910: 32]

10. Fraseología. [echar cola 'fornicar'; armar una fiesta 'combinar un robo']

En otro lugar de la "Introducción”, Vicuña retoma la idea generalizada entre los estudiosos de que el lenguaje jergal se caracterizaría principalmente por dos propiedades: "la pobreza del léxico y la abundancia extremada de la sinonimia” (1910: 14). Sobre lo primero, "se explica fácilmente por el limitado campo que abarcan las empresas delincuentes, dentro de su misma variedad; por la relativa escasez de ideas y de sensaciones de los que lo han formado, y por el carácter meramente auxiliar de sus representaciones" (1910: 38-39). De hecho, si no hubiera una abundante sinonimia, el caudal léxico de la jerga sería todavía menor.

Otra razón de peso para la pobreza léxica sería "la desigual manera como un mismo objeto hiere la imaginación de estos hombres, y la diversa asociación de ideas que en ellos provoca, que 
luego se traduce por las más variadas metáforas" (Vicuña 1910: 39). Aunque Vicuña no abunda más en esto (excepto por la discusión del ejemplo de la variación onomasiológica para llamar a la camisa: paloma y acordión), parece dejarse ver una caracterización del hablante de coa como "asocial", en el sentido de que no opera mediante consenso ordenado en la constitución de su lenguaje sino de manera atomística y hasta cierto punto caótica y caprichosa. En la misma dirección apunta la representación que el autor hace de las "formas de origen desconocido" que conforman el coa, a las que el investigador difícilmente podría llegar a atribuirles alguna racionalidad o lógica, "por haber nacido de las más profundas reconditeces del espíritu criminal” (1910: 31).

Sobre lo segundo, la sinonimia abundante, junto con apoyarse implícitamente en el lugar común evolucionista que desde Herder atribuía esta característica "innecesaria" a las lenguas "primitivas" (Errington 2008: 54), Vicuña recurre a una explicación que pone en lugar central la saturación léxica de aquellas partes del mundo que al delincuente le interesan en cuanto delincuente. Por ejemplo, si en el actuar criminal hay siempre un victimario, una víctima y un agente de la justicia, "ya se comprende que estas tres entidades deben tener abundante representación en la jerga” (1910: 34), así como la tienen el delito, los instrumentos para ejecutarlo y los objetos sobre los que se aplica. Se sobreentiende que la sinonimia abundante sería una contraparte de la pobreza léxica, pues si la atención del delincuente se concentra en ciertos elementos de su entorno, el vocabulario se concentrará allí y se descuidará la nominación en otros ámbitos.

Sin embargo, advierte contra el posible paralelo que se pueda establecer, a partir de la pobreza léxica y la sinonimia abundante, con las "lenguas primitivas" habladas por "salvajes", en el sentido de que en ambos casos la pobreza léxica y la abundante sinonimia signifiquen respectivamente "igual pobreza de actos, de ideas y de sensaciones" (1910: 15). Mientras que las lenguas primitivas son el único recurso de expresión para sus hablantes, los delincuentes son también, recuérdese, hablantes de lenguaje "normal” y, por tanto, "disponen de un léxico mucho más rico para nombrar todo aquello 
que no tienen interés en ocultar” (1910: 15). Se trataría más bien de que el delincuente "á medida que penetra en su oficio, siente estrecharse el círculo de sus ideas, actos y sensaciones” (Vicuña 1910: 16). Aclara, a renglón seguido, que no es que quiera desconocer que "el delincuente habitual es un degenerado", sino que simplemente quiere matizar "apreciaciones que se nos antojan demasiado absolutas” (1910: 17). El delincuente, a pesar de que se los quiera caracterizar como incapaces de creación (“parasitarios”), muestran a veces ingenio (aunque mal empleado en el engaño). Asimismo, si bien la mentalidad reflejada en la jerga es "casi infantil, por la simplicidad de sus representaciones, en los pequeños centros, se extiende y se complica á medida que crece el nivel intelectual del medio" (1910: 18).

A pesar de las matizaciones, es claro que Vicuña comparte la visión positivista-evolucionista del criminal como un ser humano "degenerado", y que esto tiene efecto en su manera de representar ideológicamente el coa. De forma consecuente, atribuye a las representaciones contenidas en el coa una condición de reflejo de la siquis y espiritualidad degenerada, corrupta o en cualquier otro sentido “inferior” de sus hablantes respecto de la población no delincuente. Cabe aclarar que aunque Vicuña cuestiona la idea de Cesare Lombroso sobre que el atavismo sea el principal factor que origina las jergas (lo que motiva su existencia sería el disimulo u ocultamiento), no disiente, sin embargo, respecto de que el atavismo influya fuertemente en las características lingüísticas mismas de estas variedades: así, citando a Lombroso, los delincuentes "hablan como salvajes, porque son salvajes que viven en medio de la brillante civilización europea: de allí que emplean frecuentemente, como los salvajes, la onomatopeya, el automatismo, la personificación de los objetos abstractos" (citado en Vicuña 1910: 7); recuérdese que varios de estos fenómenos son precisamente aquellos que lista Vicuña en su análisis del coa. Cuando caracteriza los automatismos del coa, los califica como manifestaciones de un "fenómeno propio de los idiomas primitivos y del lenguaje de los niños” (1910: 25). Asimismo, cuando se refiere a las "formas de origen desconocido" menciona "altera- 
ciones que el uso inculto y bárbaro ha ido introduciendo" (1910: 31). Finalmente, entre las unidades fraseológicas, "son más groseras, menos pintorescas que las francesas é italianas, por ejemplo, como hijas al fin de un pueblo atrasado y menos imaginativo", y "no hay en ellas nada que flote, nada que se exhale, y su propia pesadez las retendrá en el fondo de las capas sociales" (1910:33).

Pese al desacuerdo con el paralelo delincuente/salvaje que ya explicamos muestra Vicuña, el fondo de la idea de Lombroso es en lo que concuerda: lo que tiene de despreciable el coa se debe a lo despreciable que hay en el espíritu de los delincuentes. Recuérdese, además, que nuestro autor estipulaba que para entender cabalmente qué es una jerga es necesario "relacionarla continuamente con la condición moral é intelectual de sus autores" (1910: 12). El sintagma “espíritu criminal” (1910: 13), empleado por Vicuña, sintetiza ese principio sicológico que moldearía las características del coa y respecto del cual estas últimas serían "cristalizaciones" (1910: 13).

El autor de Coa ejemplifica la relación lengua-"espíritu” con el ejemplo del vocabulario relativo al sexo, tal como se observa en la jerga de los delincuentes chilenos:

Ya que no el amor, la actividad genésica ha debido inspirar nuevas formas de representación á la sensualidad brutal é indisciplinada de aquellos hombres. Así es, efectivamente: ninguna palabra hemos encontrado en su vocabulario que califique, en sus relaciones sexuales, un objeto noble, un sentimiento casto. Para ellos, la mujer en general es guata, aludiendo indudablemente á la posición que adopta en el coito, pues el calificativo guarda perfecta relación con el de espinazo, que designa al súcubo. La mujer es también jermu (por metátesis), guargüero; la prostituta es maraca, del nombre de cierto juego de muchachos; la felatriz es matera; pescar significa forzar, acto que también se denota con el nombre de guerrazo; ir á Colina significa ir á fornicar; la tribadista macho es planchadora; cabrito es el uranista pasivo menos de dieciocho años, y cachero, lancero designan indistintamente al invertido en general. (Vicuña 1910: 35-36) 
Desde el punto de vista de los estudios sobre ideologías lingüísticas, el vínculo entre coa (parasítico, léxicamente pobre, de modos representativos infantiles y primitivos) y "espíritu criminal” (degenerado, atávico), que según hemos visto se encuentra en el meollo de la representación que Vicuña construye sobre el lenguaje de los delincuentes chilenos, puede explicarse fructíferamente mediante el concepto de iconización propuesto por Irvine y Gal (2000).

Dicho concepto debe entenderse a partir de la conocida distinción de Charles S. Peirce entre tres tipos de signos: simbolos, vinculados con sus referentes de forma totalmente convencional; indices, vinculados por una relación de contigüidad con su referente; e íconos, vinculados por una relación de similaridad con sus referentes. La antropología lingüística ha aplicado exitosamente el concepto de índice a la comprensión del significado social de las variantes lingüísticas, entendiendo que estas pueden llegar a codificar convencionalmente ("apuntar a") sus contextos y sus usuarios; de aquí el concepto de indicialidad, entendido como "the principle of contextualization of linguistic and other signs-in-use, seen as a component of the meaning of the occurring sign-forms" (Silverstein 2009).

Silverstein (2003) ha propuesto que la indicialidad se da en distintos "órdenes": la indicialidad de primer orden sería aquella que simplemente asocia una forma lingüística con un contexto sociodemográfico específico por parte de un observador externo; en la de segundo orden, se añade una percepción reflexiva, un primer grado de conciencia metalingüística; en el tercer orden, la conciencia metalingüística se hace ideológica. En dirección al tercer orden de indicialidad, la ideologización puede hacer que la indicialidad se transforme en iconicidad. En este sentido, la naturaleza situada y contingente de la condición indicial se racionaliza y naturaliza en función de la ideología que desea construir una representación en la que los rasgos lingüísticos usados por un grupo social ya no solo son indicativos de ese grupo, sino que se entienden como reflejo de una "forma de ser" propia de ese grupo. Ya no se interpretan como asociados solo por contigüidad (una relación contingente) sino que 
por similaridad (relación motivada). En palabras de estas autoras: "Linguistic features that index social groups or activities appear to be iconic representations of them, as if a linguistic feature somehow depicted or displayed a social group's inherent nature or essence" (Irvine y Gal 2000: 37).

La propuesta de estas autoras además reviste interés para el caso que estudiamos porque responde a un intento por dilucidar las bases de la construcción ideológica de la diferencia lingüística. Primero, interesa destacar que se trata de un proceso de construcción ideológica, es decir, un recurso semiótico de acción política motivada por intereses grupales, y que por tanto implica que hay una responsabilidad de parte de los agentes que la llevan a cabo (Irvine y Gal 2000: 37). La creación de un vínculo icónico entre una forma lingüística y un significado social implica un propósito por parte del agente creador, pues en dicha creación opera un principio de atención selectiva sobre elementos similares que sirvan a la representación que se quiera hacer y el ignorar otros que no sean funcionales a la misma (Jeong 2017: 3). De ahí que, como destaca Jeong siguiendo a $\mathrm{Gal}$ (2013), deba entenderse la iconización como un "active ideological, hence semiotic, process to create a similarity, and the necessary concomitant of similarity: differentiation" (citado en Jeong 2017: 3).

El segundo aspecto de la perspectiva de Irvine y Gal (2000) directamente relevante para entender Coa de Vicuña es el énfasis en cómo este proceso se enfoca en la construcción de la diferencia, entendida como parte de la construcción de un Otro y, a la vez, del Mismo (Self) que sirve de base a la identidad social hegemónica (Jenkins 2008: 16-27). Las ciencias del lenguaje modernas fueron cruciales en la legitimación del reclamo de diferencia y superioridad de los europeos respecto de los territorios colonizados por ellos, cuyos habitantes fueron conceptualizados como "primitivos" o "atrasados", así como lo fueron para la naturalización discursiva de la superioridad de la burguesía metropolitana sobre habitantes de las provincias o sobre otras clases sociales, a quienes se atribuyeron similares características (Irvine y Gal 2000: 73). Precisamente, en 
este último punto es donde las dinámicas de aquel contexto encuentran un análogo en el Chile de fines del siglo XIX.

Es crucial, para apreciar correctamente hasta qué punto llega la analogía con el caso de Vicuña, que ya a mediados del siglo XIX, se había hecho hegemónica en la lingüística la visión institucionalista del lenguaje (según la denominación de Taylor 1990), es decir, la presuposición de que el lenguaje existe "fuera" de sus hablantes como institución social y que, por tanto, es posible estudiarlo de forma “objetiva” mediante procedimientos similares a los de las ciencias naturales, lo cual coincide con el auge del positivismo y el biologicismo en la disciplina (Swiggers 2011). Al convertir el objeto de estudio en un fenómeno natural, "linguistic differences appeared to be 'natural' consequences of spiritual or even biological differences between collectivities of speakers rather than consequences of social action" (Irvine y Gal 2000: 73).

No es casualidad, considerando lo anterior, que la forma del discurso que adopta la acción de la SFCh en esta obra en particular siga las convenciones propias del discurso científico. Si el estudio del coa se presenta discursivamente bajo la forma de la ciencia, mayor éxito tendrá la naturalización de la construcción del Otro subalterno como un sujeto deficiente desde distintos puntos de vista; es decir, mayor probabilidad hay de alcanzar el efecto (gloto)político deseado. La supresión u ocultamiento de la subjetividad propia de toda interpretación es funcional a ese fin.

Nótese primero que la parte más voluminosa de la obra, el vocabulario, viene a cumplir la función de evidencia respecto del análisis del coa que Vicuña ofrece en la introducción. Se adopta así una estructura demostrativa de tipo inductivo, según la cual los ítems léxicos son la base empírica que permite sacar las conclusiones ofrecidas por el autor. No se trata, entonces, de un simple estudio filosófico, imposible de someterse a verificación o desestimable por su condición eminentemente subjetiva. Es un análisis que puede reclamar para sí la condición de verdad comprobable científicamente. Nótese que solo por tener su autor la confianza en que su análisis es certero es que puede hacer la estrategia retórica de 
someterse al juicio del lector: "La lectura del vocabulario permitirá ahora á los que no hayan acompañado hasta aquí, juzgar del mayor ó menor acierto con que hemos discurrido" (Vicuña 1910: 41). Más aun, el análisis está "ahí", en el propio material empírico, lo cual hace el análisis más evidente, hasta el punto de que el autor puede afirmar que hace su exposición "con arreglo á la clasificación que su propio estudio [el del material empírico] nos sugiere" (Vicuña 1910: 20).

Segundo, el propio análisis que ofrece Vicuña respecto de los tipos de fenómenos representados en el coa (el esquema que ya reprodujimos unas páginas atrás) conlleva la operación de disección minuciosa y clasificación que es característica del positivismo de la lingüística histórico-comparada del siglo XIX, escuela paradigmática del cientificismo lingüístico en esa época y que pretendía describir y explicar el lenguaje "de acuerdo con protocolos homologables a los de las ciencias naturales" (Del Valle 2017: 30), como serían justamente la disección y clasificación de la materia empírica (en este caso, el vocabulario del coa). Volviendo a la caracterización que Taylor (1990) hace de los procedimientos de la lingüística decimonónica que afianza la visión institucionalista, es justamente en ella donde cobra sentido el tipo de análisis que presenta Vicuña:

En este marco teórico, la identificación de los rasgos de la institución (los mecanismos de producción de sentido del lenguaje o de una lengua) le corresponde a especialistas en posesión de recursos que le permitan realizar una descripción correcta. La autoridad aquí es la experta o el experto y su legitimidad depende de su destreza para la producción de la representación y explicación verdadera. (Del Valle 2017: 29)

En tercer lugar, el propio discurso lexicográfico se configura en torno a enunciados que parecen simples descripciones del significado y las condiciones de uso de las unidades léxicas del coa. En la lexicografía chilena de fines del XIX, campeaba el normativismo y un modo discursivo más bien periodístico o ensayístico, necesario para demostrar o refutar la condición correcta o incorrecta de 
los usos léxicos chilenos. También, es característica de dicha tradición el uso de definiciones sinonímicas, que cumplen la función de ofrecer al lector un sustituto para ser usado en lugar de los vocablos identificados como incorrectos (Rojas 2010: 222-224). En cambio, las formas lexicográficas de Coa de Vicuña se asemejan, por su concisión, uso de abreviaturas y fidelidad a la fórmula aristotélica de la definición conceptual, a la tradición lexicográfica central, no necesariamente normativa, de la lexicografía europea. El autor evita, al definir (intencionalmente, según nuestra interpretación), el uso de elementos léxicos que muestren abiertamente valoraciones acerca de los referentes a los que se alude o respecto de los usos lingüísticos mismos que se comentan. Con esto, intenta construir una voz autorial “objetiva”, y, por tanto, “científica”. Puede apreciarse este patrón en los siguientes ejemplos:

Hacer sudar. fr. Atacar entre muchos a uno solo.

Niñoco. m. Ladrón camorrista muy audaz.

Ronchar. a. Sorprender in fraganti a un ladrón.

Para terminar nuestro análisis haciendo una conexión entre las formas del discurso lexicográfico y la construcción de la diferencia lingüística, podemos llamar la atención sobre el modo lexicográfico diferencial al que corresponde la selección de la nomenclatura en Coa. En general, como vimos, en el Programa de la SFCh hay una perspectiva diferencial subyacente a los objetos de estudio definidos por la Sociedad, con claras consecuencias ideológicas. Enfocarse en caracterizar solo lo que diferencia a un grupo de hablantes conlleva una actitud reduccionista de su identidad idiomática y peyorativa respecto de sus características, pues habitualmente se termina definiéndolos en su relación con un grupo arbitrariamente designado “normal” y que en realidad corresponde a la clase dominante.

En Coa, opera la misma lógica, pues las unidades léxicas que conforman la nomenclatura, las que definen la identidad de los hablantes de coa, son solo aquellas que los diferencian respecto de la sociedad normal. El efecto ideológico es doble si se tiene en cuenta 
que, además de la visión esencialista y normativa del delincuente que lo anterior implica, resulta que los campos conceptuales a los que pertenecen los vocablos recogidos en el vocabulario de la obra también reflejan de manera isomórfica la reducción al delito que se supone propia del "espíritu criminal”. Así es como en el análisis de Vicuña el vocabulario se concentra de forma preferente en los actores y objetos que cumplen una función en relación con la comisión del delito: la víctima, el victimario, el funcionario de la justicia, junto con las referencias "al delito mismo, á los objetos que son materia de él y á los instrumentos de que se valen para consumarlo", además de "los nombres con que designan las penas y castigos á que los conduce su arriesgada profesión” (1910: 35).

\section{Conclusión}

En un contexto histórico en que las transformaciones económicas y sociales acaecidas en el Chile de fines del XIX y comienzos del XX habían suscitado la "cuestión social" de una forma ineludible para las élites dominantes, la actividad científica se transforma en un importante mecanismo de intervención en el problema, tanto en cuanto dispositivo de conocimiento al servicio de los aparatos disciplinadores del Estado, como en cuanto dispositivo de naturalización de una representación negativa del subalterno. Las obras de la Sociedad de Folklore Chileno forman parte de este operativo de domesticación del Otro. En el caso del estudio del coa, que formaba parte integrante de los focos de interés de la SFCh según quedaron manifestados en su Programa, este sociolecto opera como un puente metonímico a través del cual se intenta "imaginar" de cierta forma a las clases subalternas urbanas, construyéndolos al mismo tiempo como un Otro radicalmente diferenciado de la población "normal", pero, paradójicamente, al mismo tiempo parte integrante de la nación, aunque sea como un "parásito" indeseable y que representa un estadio primitivo de la evolución humana. De esta manera, se naturaliza, mediante el recurso semiótico-ideológico de la iconización lingüística, una imagen negativa de los sectores 
populares a través de los discursos acerca de la lengua, revelándose así el sentido glotopolítico de la obra que analizamos. Llegar a esta conclusión, por cierto, requiere aceptar la hipótesis (que merece ser examinada con más amplias evidencias) de que el delincuente, para las élites chilenas, representa metonímicamente a la generalidad de los sectores subalternos, mediante una operación de homogenización radical del otro.

De acuerdo con lo dicho, las representaciones sobre el lenguaje contenidas en Coa de Vicuña son ideológicas en la medida en que sirven a los intereses políticos de un grupo social específico, y, como suele suceder con la ideología dominante (Bourdieu y Boltanski 2009), por presentarse bajo una forma de discurso "verdadero", el que, por el contexto histórico-situacional específico en que se sitúan su autor (modernización del Estado sobre principios positivistas), abraza el cientificismo como garante de dicha veracidad. La ciencia antropológica y lingüística chilena de ese momento, entonces, desempeña un papel importante en la afirmación de una posición hegemónica por parte de las élites chilenas castellanohablantes. Se trata, en el fondo, de una reacción de las clases dominantes respecto de la interrogante de cómo (ya que parecía inevitable) incorporar al "vulgo" en la nación, pero sin que esto perturbara el orden establecido con esfuerzo y pasión por la oligarquía chilena decimonónica.

Lo dicho sobre esta obra en particular parece responder en general al patrón que se puede identificar en la producción lingüística moderna sobre los llamados argots, en la medida en que "la regulación del mercado lingüístico a través de la identificación de sus formas más o menos legítimas, de la indexación de las variantes existentes, permite otorgar realidad a la concepción social y política en la que se inscriben” (Ennis 2017: 225). Así es cómo se logra estratificar la sociedad de tal forma que "los subalternos hablen de modos que hacen necesaria su subordinación” (Ennis 2017: 225). En este sentido, Ennis describe con precisión la condición de los argots, según los imagina la lingüística moderna tanto en Europa como en América Latina, como una condición liminar: "simultánea exterioridad e interioridad, marginalidad incluida en un espacio que 
se pretende sin afuera, [...] siempre dentro de los límites asignados a la lengua que se ha dado a la nación y por cuya unidad velará el Estado” (2017: 242).

\section{Referencias bibliográficas}

Arnoux, Elvira

2000 "La Glotopolítica: transformaciones de un campo disciplinario". En Lenguajes: teorías y prácticas. Ed., Alfredo Rubione. Buenos Aires: Instituto Superior del Profesorado "Joaquín V. González”, 3-27.

Arnoux, Elvira

2006 Análisis del discurso: modos de abordar materiales de archivo. Buenos Aires: Santiago Arcos.

Arnoux, Elvira, José Del Valle y Alexandre Duchêne (eds.)

2019 "Glotopolítica - Langage et luttes sociales dans l'espace hispano-lusophone”. Glottopol. 32.

BOURdieu, Pierre y Luc Boltanski

2009 La producción de la ideología dominante. Trad., H. Cardoso. Buenos Aires: Nueva Visión.

BuZeK, Ivo

2011 Historia crítica de la lexicografía gitano-española. Brno: Masarykova Univerzita.

Calera, Andrés

1986 "Rafael Salillas: medio siglo de antropología criminal española”. LLULL. 9. 81-104.

Carreras, Sandra y Katja Carrillo Zeiter (eds.)

2014 Las ciencias en la formación de las naciones americanas. Madrid/Frankfurt: Iberoamericana/Vervuert.

Cavada, Francisco

1914 Chiloé y los chilotes. Estudios de folklore y lingüistica de la provincia de Chiloé (República de Chile) acompañados de un vocabulario de chilotismos y precedido de una breve Reseña Histórica del Archipiélago. Santiago: Imprenta Universitaria. [reedición: 2016, Ediciones Museo Regional de Ancud.] 
Cavada, Francisco

1921 Diccionario manual isleño. Provincialismos de Chiloé (Chile). (De gran utilidad para los profesores de castellano y para los viajeros que visitan la región austral del pais). Santiago: Imprenta Yolanda.

CHen, Wenge

2019 "Towards a discourse approach to Critical Lexicography". International Journal of Lexicography. 32. 3, 362-388. <https:// doi.org/10.1093/ijl/ecz003>

CLAVE

s/f Diccionario Clave. Diccionario de uso del español actual. Editorial SM. Consultado: 23 de abril de 2019. <http://clave. smdiccionarios.com/app.php>

Coleman, Julie

2004-2010 A History of Cant and Slang Dictionaries. Vols. I-IV. Oxford: Oxford University Press.

Collier, Simon y William SATER

1998 Historia de Chile, 1808-1994. Santiago: Cambridge University Press.

Dannemann, Manuel

2010 "Tres buscadores de la chilenidad: Lenz, Laval y Vicuña Cifuentes". Anales de Literatura Chilena. 11. 14, 57-92.

Del Valle, José

2019 "Departments and disciplinary gatekeeping: the sociolinguistics of Spanish in US Academia”. En Insights from the Social Sciences. Consultado: 19 de junio de 2019. $<$ https://items.ssrc.org/departments-and-disciplinary-gatekeeping-the-sociolinguistics-of-spanish-in-us-academia/>

Del Valle, José

2017 "La perspectiva glotopolítica y la normatividad". Anuario de Glotopolítica. 1. 17-39.

Del Valle, José y Vitor Meirinho-Guede

2016 “Ideologías lingüísticas”. En Enciclopedia de lingüística hispánica. Vol. 2. Ed., Javier Gutiérrez-Rexach. London y New York: Routledge, 622-631. 
ENNIS, Juan Antonio

2016 "Rodolfo Lenz: economías de la lengua y políticas de la lingüística”. Boletín de Filología. 51. 1, 117-145. <https://doi. org/10.4067/S0718-93032016000100004>

ENNIS, Juan Antonio

2017 "La lingüística moderna y los límites del argot: miradas desde el siglo XIX”. En Argots hispánicos. Analogías y diferencias en las hablas populares hispanoamericanas. Ed., Óscar Conde. Remedios de Escalada: Universidad Nacional de Lanús, 219244.

ERRINGTON, Joseph

2008 Linguistics in a colonial world. A story of language, meaning, and power. Malden: Blackwell.

Felluga, Dino Franco

2015 Critical Theory. The key concepts. London/New York: Routledge.

FERnÁNDEZ, M. ${ }^{a}$ Dolores

1976 Elpensamiento penitenciario y criminológico de Rafael Salillas. Santiago de Compostela: Universidad de Santiago de Compostela.

GREZ, Sergio

1995 "Estudio crítico". En La “cuestión social” en Chile. Ideas y debates precursores (1804-1902). Ed., Sergio Grez. Santiago: DIBAM, 9-41.

Halliday, M. A. K

2001 "Antilenguajes". En El lenguaje como semiótica social. La interpretación social del lenguaje y del significado. Buenos Aires: Fondo de Cultura Económica de Argentina, 215-238.

Harris, Roy y George Wolf (eds.)

1998 Integrational linguistics: a first reader. Oxford: Pergamon.

Huisa, José Carlos

2013 "La impronta política en la primera lexicografía hispanoamericana: republicanismo y antirrepublicanismo". Lexis. 37. 2, 269-303. 
IRvine, Judith y Susan GAL

2000 "Language Ideology and Linguistic Differentiation". En Regimes of Language: Ideologies, Politics, and Identities. Ed., Paul V. Kroskrity. Oxford: Oxford University Press, 35-84.

JENKINS, Richard

2008 Social identity. 3. ${ }^{\mathrm{a}}$ ed. New York: Routledge.

JeONG, Sunwoo

2017 "Iconization of Sociolinguistic Variables: The Case of Archetypal Female Characters in Classic Hollywood Cinema”. En Dimensions of iconicity. Eds., Angela Zirker et al. Amsterdam: John Benjamins, 263-286.

JosepH, John E.

2017 "De cómo la política impregna el lenguaje (y viceversa). Visión panorámica”. Anuario de Glotopolítica. 1. 279-312.

Joseph, John E. y Talbot J. TAYLOR

1990 "Introduction: ideology, science and language". En Ideologies of language. Dirs., John E. Joseph y Talbot J. Taylor. London/ New York: Routledge, 1-6.

Laurendeau, Paul

1990 "Theory of Emergence: toward a historical-materialistic approach to the history of linguistics". En Ideologies of language. Dirs., John E. Joseph y Talbot J. Taylor. London/New York: Routledge, 206-220.

LAURIA, Daniela

2011 "Apuntes para una historia de la producción lexicográfica monolingüe en la Argentina: etapas del proceso de diccionarización y modalidades diccionarísticas entre 1870 y 1910”. Boletín de Filología. 46. 1, 106-150.

LENZ, Rodolfo

[1905-1910] 1979 Diccionario etimológico de voces chilenas derivadas de lenguas indígenas americanas. Edición dirigida por Mario Ferreccio Podestá. Santiago: Universidad de Chile.

LENZ, Rodolfo

1909 Programa de la Sociedad de Folklore Chileno. Santiago: Imprenta y Encuadernación Lourdes. 
LeÓn, Marco Antonio

2015a Construyendo un sujeto criminal. Criminología, criminalidad $y$ sociedad en Chile. Siglos XIX y XX. Santiago: Editorial Universitaria.

León, Marco Antonio

2015b "Definiendo una antropología para el criminal en el Chile finisecular (siglos XIX-XX)”. Alpha. 40, 53-70.

Makoni, Sinfree y Alastair PenNycook (eds.)

2007 Disinventing and reconstituting languages. Clevedon: Multilingual Matters.

Matus, Alfredo

1994 "Períodos de la lexicografía diferencial del español de Chile". En Actas del X Congreso de la Asociación de Academias de la Lengua Española. RAE/Espasa Calpe, 189-199.

MORA, Héctor

2018 "Construcción de la nación y ciencia republicana: condiciones de posibilidad del 'araucanismo'”. En Elpueblo mapuche en la pluma de los araucanistas. Seis estudios sobre construcción de la alteridad. Eds., Héctor Mora y Mario Samaniego. Santiago: Ocholibros, 131-166.

Pavez, Jorge

2015 "La lengua de Chile: Rodolfo Lenz entre chilenos y mapuches". En Laboratorios etnográficos. Los archivos de la antropología en Chile (1880-1980). Santiago: Ediciones Universidad Alberto Hurtado, 67-167.

Pecheux, Michel

[1975] 2017 Las verdades evidentes. Lingüistica, semántica, filosofía. Buenos Aires: Ediciones del CCC.

PINTO, Jorge

2008a "Proyectos de la elite chilena del siglo XIX (I)". ALPHA. 26, 167-189.

PinTO, Jorge

2008b "Proyectos de la elite chilena del siglo XIX (II)". ALPHA. 27, 123-145. 
Rodríguez Barcia, Susana

2016 "Lexicografía crítica". En Introducción a la lexicografía. Madrid: Síntesis, 255-302.

Rojas, Darío

2010 "Estandarización lingüística y pragmática del diccionario: forma y función de los «diccionarios de provincialismos» chilenos”. Boletín de Filología. 45. 1, 209-233.

Rojas, Darío

2011 "Voces usadas en Chile (1900): las cartas de Aníbal Echeverría y Reyes a Rodolfo Lenz”. Onomazein. 24. 2, 349-361.

Rojas, Darío

2015 "Ideologías y actitudes lingüísticas en el Chile hispanohablante de la segunda mitad del siglo XIX”. Tesis doctoral. Universidad de Valladolid.

Rojas, Darío

2017 "Representaciones del cambio lingüístico en Chile durante el siglo XIX: «¿progreso o decadencia?»”. Literatura y Lingüistica. 36, 243-262.

SAnHuEza, Carlos

2013 "La gestación del Instituto Pedagógico de Santiago y la movilidad del saber germano a Chile a finales del siglo XIX”. Estudos Ibero-Americanos. 39. 1, 54-81. <https://doi. org/10.15448/1980-864X.2013.1.12961>

SALILlas, Rafael

1896 El delincuente español: el lenguaje (estudio filológico, psicológico y sociológico). Con dos vocabularios jergales. Madrid: Librería de Victoriano Suárez.

Silva Castro, Raúl

1944 "Julio Vicuña Cifuentes (1865-1936)". En Revista Iberoamericana. 7. 14, 453-457. <https://doi.org/10.5195/ REVIBEROAMER.1944.3315>

Silverstein, Michael

2003 "Indexical order and the dialectics of sociolinguistic life". Language and Communication. 23, 193-229. <https://doi. org/10.1016/S0271-5309(03)00013-2> 
Silverstein, Michael

2009 "Pragmatic Indexing”. En Concise Encyclopedia of Pragmatics. $2^{a}$ ed. Ed., Jacob L. Mey. Amsterdam: Elsevier, 756-759.

SORENSEN, Janet

2017 Strange vernaculars. How eighteenth-century slang, cant, provincial languages, and nautical jargon became English. Princeton/Oxford: Princeton University Press.

Subercaseaux, Bernardo

2007 "Raza y nación: el caso de Chile". A Contracorriente. 5. 1, 29-63.

Subercaseaux, Bernardo

2011 Historia de las ideas y la cultura en Chile: desde la Independencia hasta el Bicentenario. Santiago: Editorial Universitaria.

SWIGgers, Pierre

2011 "19 $9^{\text {th }}$ century linguistics: practice and theory". En The languages and linguistics of Europe: a comprebensive guide. Eds., Bernd Kortmann y Johan Van der Auwera. Berlin/ Boston: Walter de Gruyter, 805-820.

Swiggers, Pierre

2018 "De la ideología de la(s) lengua(s) a la(s) ideología(s) de la lingüística”. Circula: Revne d'Idéologies Linguistiques. 8, 70-101.

TAYLOR, Talbot J.

1990 "Which is to be master? The institutionalization of authority in the science of language". En Ideologies of language. Dirs., John E. Joseph y Talbot J. Taylor. London/New York: Routledge, 9-26.

TAYLOR, Talbot J.

1997 "Roy Harris and the philosophy of linguistics". Language Sciences. 19. 1, 1-5. <https://doi.org/10.1016/03880001(95)00021-6>

Thompson, John B.

1984 Studies in the theory of ideology. Berkeley/Los Angeles: University of California Press.

VICUÑA, Julio

1910 Coa: jerga de los delincuentes chilenos: estudio y vocabulario. Santiago: Imprenta Universitaria. 
482 Lexis Vol. XLIV (2) 2020

ZimMERMANN, Klaus

2018 "Lexicografía diferencial y lexicografía integral”. En Léxico dialectal y lexicografía den la Iberorromania. Eds., María Álvarez de la Granja y Ernesto González Seoane. Madrid/ Frankfurt: Iberoamericana/Vervuert, 121-144.

Recepción: 07/11/2019

Aceptación: 26/03/2020 